\title{
PEMANFAATAN GEOBOARD DAN KARET GELANG UNTUK MENINGKATKAN MINAT BELAJAR SISWA PADA BANGUN DATAR
}

\author{
Istikomah \\ SD Negeri Krejengan Kabupaten Probolinggo \\ istikomah19640818@gmail.com
}

\begin{abstract}
Abstrak
Kurangnya minat siswa dalam mempelajari matematika merupakan suatu momok yang perlu segera untuk ditindaki. Pada penelitian ini, peneliti menggunakan media geoboard dan karet gelang sebagai alat untuk meningkatkan minat belajar tersebut. Penelitian dilakukan dengan Penelitian Tindakan Kelas yang berhasil diselesaikan dalam dua siklus. Hasil dari penelitian ini adalah meningkatnya minat belajar siswa pada matematika yang sebelum melakukan tindakan hanya diminati oleh 12 siswa, setelah dilakukan siklus I dan II menjadi 20 siswa yang berminat dari total siswa sejumlah 22 . Peningkatan hasil belajar dan pemahaman konsep pun sangat baik. Pada akhir tindakan di siklus II didapati bahwa seluruh siswa telah paham terhadap konsep hitung luas dan keliling bangun datar segi empat dan segitiga.
\end{abstract}

Kata kunci: geoboard, minat belajar, segiempat, segitiga

\begin{abstract}
Lack of student interest in learning mathematics is a scourge that needs immediate action. In this study, researchers used the media geoboard and rubber bands as a tool to increase interest in learning. The study was conducted with Classroom Action Research which was successfully completed in two cycles. The results of this study are increased student interest in mathematics before taking action only 12 students, after cycles I and II, made 20 students interested in a total of 22 students. Increasing learning outcomes and concept understanding was very good. At the end of the action in the second cycle it was found that all students had understood the concept of calculating area and circumference of rectangular and triangular shapes.
\end{abstract}

Keywords: geoboards, learning interests, squares, triangles

\section{PENDAHULUAN}

Minat belajar dalam mempelajari matematika merupakan hal yang sangat penting dan harus ada dalam diri siswa. Minat merupakan elemen inti yang menggerakkan motivasi internal individu untuk melakukan atau mencapai sesuatu (Widyastuti, Wijaya, Rumite, Marpaung, 2019). Minat belajar mempunyai pengaruh yang besar terhadap prestasi belajar siswa. Jika 


\section{Istikomah}

Pemanfaatan Geoboard dan Karet Gelang untuk Meningkatkan Minat Belajar Siswa pada Bangun Datar

siswa malas, tidak ada keinginan untuk belajar, dan mengalami kegagalan, maka penyebabnya adalah karena kurangnya minat belajar. Maka dari itu, minat belajar matematika perlu mendapatkan perhatian khusus.

Tinggi atau rendahnya minat belajar siswa pada matematika bisa dilihat dari beberapa indikator. Beberapa indikator tersebut, diantaranya adalah perhatian, keinginan, kesenangan, kesungguhan, dan kepuasan yang ditunjukkan oleh siswa ketika proses pembelajaran matematika dilangsungkan. Namun demikian, yang ditemui peneliti di lapangan dalam pembelajaran matematika di sekolah, siswa kadangkala menganggap matematika sebagai pelajaran yang memusingkan. Tidak jarang juga didapati siswa mengalami ketakutan saat pelajaran matematika.

Di SD Negeri Krejengan Kabupaten Probolinggo, peneliti melihat persepsi negatif siswa pada pelajaran matematika. Hal tersebut rupanya berdampak buruk pada minat siswa untuk belajar matematika. Jika siswa memiliki persepsi bahwa matematika adalah pelajaran yang sulit dan membosankan, maka siswa akan malas belajar dan cenderung mempersulit hal-hal yang mudah pada pelajaran matematika sehingga minat belajar matematika siswa akan semakin rendah (Utami, 2013). Untuk mengatasi hal itu, Sitorus dan Siburian (2013) menyatakan, pembelajaran dan pemahaman konsep matematika bisa diawali dengan cara induktif melalui pengalaman peristiwa yang nyata.

Berdasarkan pengamatan yang mendalam, hal tersebut bisa terjadi karena pembelajaran yang kurang inovatif, strategi pembelajaran yang masih monoton, dan metode pembelajaran yang kurang menarik. Hal tersebut seperti yang diungkap Silviani, Jailani, Lusyana, Hadi (2017) bahwa minat belajar matematika dapat dipengaruhi oleh faktor eksternal seperti penggunaan metode pembelajaran yang diterapkan oleh guru di dalam kelas. Pembelajaran yang digunkan hendaknya inovatif, sesuai dengan materi pelajaran yang disampaikan dan mampu diterima oleh siswa (Purba, 2017).

Generasi milenial seperti sekarang ini, guru tidak bisa fokus pada buku teks saja. Menjelaskan materi hanya melalui kata-kata, tentu akan memberikan kebosanan pada siswa. Siswa akan jenuh dengan penggunakan pensil dan buku. Perlu adanya terobosan-terobosan baru yang inovatif demi mengubah persepsi negatif dan menarik minat belajar siswa pada matematika.

Demi membuat terobosan baru agar matematika menjadi suatu hal yang menyenangkan bagi siswa sekolah dasar, maka penelitian yang diusung saat ini adalah dengan pemanfaatan geoboard dan karet gelang pada pembelajaran matematika materi bangun datar untuk siswa kelas 3 Sekolah Dasar. Geoboard dan karet gelang tersebut ditujukan untuk meningkatkan minat belajar matematika siswa. 


\section{Istikomah}

Pemanfaatan Geoboard dan Karet Gelang untuk Meningkatkan Minat Belajar Siswa pada Bangun Datar

\section{METODE PENELITIAN}

Penelitian ini merupakan penelitian tindakan kelas. Hal ini berdasar pada karakteristik penelitian tindakan kelas menurut Basonggo, Tangkas, Said (2015) yaitu masalah penelitian yang akan dipecahkan berasal dari persoalan praktik pembelajaran di kelas atau juga berangkat dari permasalahan praktik faktual. Model penelitian tindakan kelas pada penelitian ini merujuk pada model Kemmis \& MC Taggart. Penelitian melalui empat prosedur yaitu perencanaan, tindakan, observasi, dan refleksi.

Prinsip Penelitian Tindakan Kelas menurut Susilowati (2018) antara lain: terlihat adanya upaya untuk meningkatkan mutu professional guru, tampak dalam unjuk kerja siswa, seluruh siswa dalam suatu kelas terlibat, permasalahan muncul di kelasnya, penelitian berlangsung dalam siklus, penelitiannya tentang cara,prosedur,metode atau strategi, tindakan yang diberikan berbeda dari biasanya, tindakan berpijak dari kondisi nyata, tindakan merupakan kesepakatan bersama antara guru dan siswa, terdapat pengamatan oleh kolaborator atau teman sejawat, terdapat evaluasi hasil sebagai konsekuensi dari proses, penerapan instrument sesuai indikator, dan refleksi dilakukan sebagai perenungan bersama atas tindakan dan hasil yang dicapai.

Penelitian tindakan kelas ini dilaksanakan di SD Negeri Krejengan Kabupaten Probolinggo. Subjek penelitian adalah siswa kelas 3 sejumlah 10 siswa laki-laki dan 12 siswa perempuan. Penelitian dilaksanakan pada semester genap tahun ajaran 2018/2019. Materi yang dibahas dalam penelitian ini adalah luas dan keliling bangun datar segiempat dan segitiga.

Teknik pengumpulan data diperoleh melalui wawancara, pengamatan, dan tes hasil belajar yang diberikan pada setiap akhir tindakan. Kriteria siklus dalam penelitian tindakan kelas ini adalah siklus dinyatakan berhasil dan dihentikan apabila sudah tidak lagi ditemukan kesalahan konsep dalam menghitung luas dan keliling bangun datar segi empat dan segitiga, ketuntasan belajar secara klasikalnya telah mencapai $\geq 75 \%$, dan minat belajar siswa yang diperoleh dari hasil wawancara dan pengamatan meningkat.

\section{HASIL DAN PEMBAHASAN}

Penelitian diawali dengan membuat perencanaan yaitu menyiapkan rencana pelaksanaan pembelajaran, lembar kerja siswa, lembar observasi siswa dan guru, serta menyiapkan media pembelajaran berupa geoboard dan karet gelang. Geoboard adalah alat bantu yang digunakan untuk mengajarkan konsep geometri, diantaranya adalah konsep menghitung keliling dan luas sebuah bangun datar (Sundayana, 2016). 


\section{Istikomah}

Pemanfaatan Geoboard dan Karet Gelang untuk Meningkatkan Minat Belajar Siswa pada Bangun Datar

Lastrijanah, dkk (2017) memberikan cara membuat geoboard adalah potong dua buah tripleks berukuran sama, lalu tempelkan kedua tripleks tersebut dengan menggunakan lem kayu. Jika sudah kering, ampelas pinggiran triplek agar halus. Setelah itu, warnai dengan menggunakan pilok. Jika cat pilok sudah kering, buatlah persegi kecil berukuran serupa dengan menggunakan mistar dan spidol, kemudian tancapkan paku-paku yang telah disediakan tepat di setiap pertemuan garis. Namun demikian, pada penelitian ini geoboard yang digunakan peneliti adalah geoboard yang biasa dijual di pasaran.

Pembelajaran dirancang dalam tiga kali pertemuan dengan materi menghitung luas dan keliling bangun datar segiempat dan segitiga. Pada setiap pembelajaran disediakan lembar kerja siswa (LKS) yang menuntun siswa untuk dapat menggunakan geoboard dan karet gelang dalam proses pembelajaran. Kelas dibagi menjadi enam kelompok, masing-masing kelompok terdiri dari 3-4 siswa. Setiap kelompok menerima satu geoboard dan beberapa karet gelang. Geoboard dan karet gelang merupakan suatu media pembelajaran yang disebutkan Dolhasair, dkk (2017) untuk membangkitkan motivasi dan minat siswa, membantu siswa meningkatkan pemahaman, menyajikan data dengan menarik dan terpercaya, serta memudahkan penafsiran data, dan memadatkan informasi.

Tahap tindakan berjalan sesuai RPP yang disiapkan dalam tahap perencanaan. Pembelajaran diawali dengan memberikan penjelasan terkait dengan materi yang akan dipelajari, lalu memeriksa kesiapan siswa mengikuti pembelajaran dengan mengulang kembali materi prasyarat yang sudah dipelajari sebelumnya. Selanjutnya, siswa dengan bimbingan guru melakukan kegiatan pembelajaran sesuai instruksi yang tertera pada lembar kegiatan siswa.

Siswa akan mengaitkan karet gelang pada geoboard sesuai instruksi pada lembar kegiatan siswa. Pembelajaran pada siklus I adalah segiempat. Salah satu geoboard hasil kerja siswa tertera dalam gambar 1 berikut.

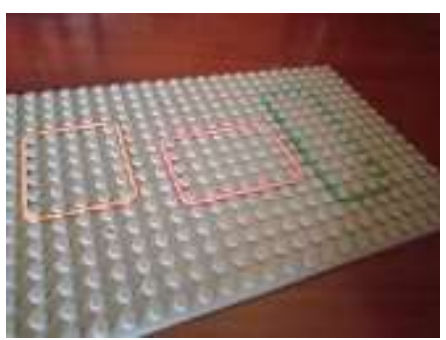

Gambar 1 Segiempat pada Geoboard 


\section{Istikomah}

Pemanfaatan Geoboard dan Karet Gelang untuk Meningkatkan Minat Belajar Siswa pada Bangun Datar

Melalui media geoboard dan karet gelang tersebut, siswa dapat benarbenar mengerti secara riil bahwa keliling adalah sejumlah bagian luar paku yang dilewati oleh karet gelang. Keliling itu seperti karet gelang yang ditempelkan pada geoboard. Sementara luas adalah sejumlah paku yang berada di dalam karet gelang dan yang mengenai karet gelang. Daerah bangun datar yang dicakup dalam luasan tersebut tertutup penuh tanpa celah dengan batasan-batasan pada tepinya (Syahbana, 2014).

Peneliti memperhatikan bahwa dengan menggunakan media geoboard dan karet gelang ini siswa tampak sangat berminat dalam belajar. Berdasarkan lima indikator ketercapaian minat, yaitu perhatian, keinginan, kesenangan, kesungguhan, dan kepuasan yang disampaikan siswa melalui hasil wawancara mengalami peningkatan setelah tindakan dilakukan. "Lebih senang sekarang, belajar sambil mengaitkan karet dan manghitung paku," demikian ungkapan dari AF, siswa dalam objek penelitian. Siswa DT pun mengatakan, "Tidak bosan belajar seperti ini. Jadi ingin belajar terus." Fifko (2017) menyatakan bahwa salah satu pembelajaran yang dapat membangkitkan minat belajar siswa adalah memberikan kesan matematika tidak sulit. Dengan demikian, manfaat dari penggunaan media ini terpenuhi.

Pada siklus II materi yang dibahas adalah mengenai segitiga seperti yang tertera pada gambar 2 berikut.

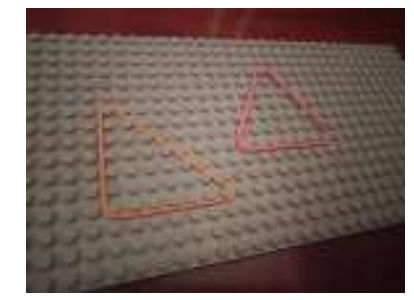

Gambar 2 Segitiga pada Geoboard

Dari hasil observasi selama penelitian, terlihat bahwa penggunaan media papan berpaku sangat membantu dalam pelaksanaan pembelajaran. Suasana belajar menjadi menyenangkan, siswa lebih mudah memahami materi yang dipelajari, dan guru lebih mudah dalam mengajar matematika. Sesuai dengan pernyataan Keraf (2017) bahwa kegunaan dari media papan berpaku adalah sebagai alat bantu pengajaran matematika di sekolah dasar untuk menanamkan konsep pengertian geometri.

Melalui hasil refleksi pada siklus I didapati bahwa masih ada beberapa siswa yang tidak tuntas dengan pemahaman konsep keliru, diantaranya adalah kesalahan siswa dalam menghitung keliling bangun persegi panjang. Dalam hal ini, kesalahan yang didapati adalah siswa menghitung jumlah paku yang dilintasi karet gelang pada geoboard. Padahal seharusnya tidak demikian kerena satu paku mengandung arti satu satuan. Jadi perhitungan 


\section{Istikomah}

Pemanfaatan Geoboard dan Karet Gelang untuk Meningkatkan Minat Belajar Siswa pada Bangun Datar

keliling yang tepat serusnya adalah menghitung bagian sisi luar paku yang terkena karet gelang. Meski nilai ketuntansan secara klasikal telah terpenuhi dan minat belajar cukup baik, tapi sesuai dengan kriteria siklus yang telah ditetapkan, maka siklus dikatakan tidak berhasil. Dengan demikian, pembelajaran dilanjutkan pada siklus berikutnya. Sementara pada siklus 2 sudah tidak ditemui siswa yang melakukan kesalahan konsep dalam menentukan luas dan keliling segitiga dan segiempat, ketuntasan belajar secara klasikal terpenuhi, serta minat belajar siswa yang semakin meningkat. Maka sesuai dengan kriteria siklus, siklus 2 dinyatakan telah berhasil. Dengan demikian siklus dihentikan.

Hasil refleksi tertuang dalam diagram 1 berikut.

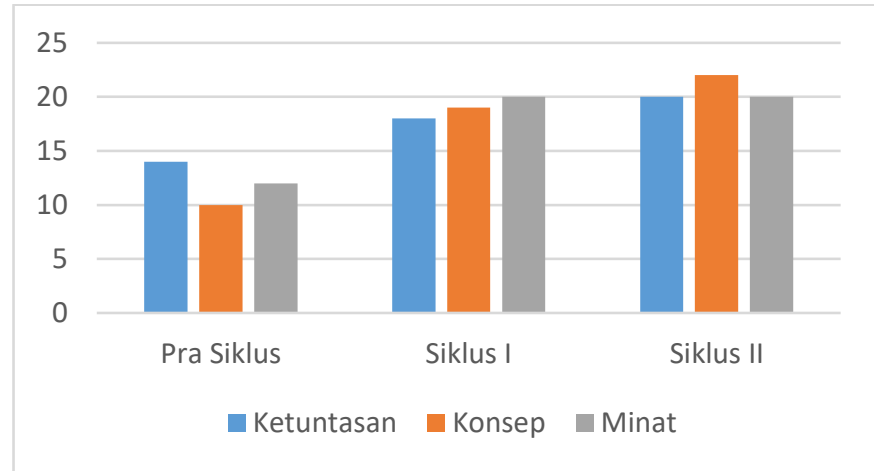

\section{Diagram 1 Banyak Siswa yang Tuntas dalam Pembelajaran}

Berdasarkan hasil penelitian ini, peneliti menyimpulkan bahwa peningkatan hasil belajar yang terjadi merupakan dampak dari perubahan aktivitas siswa selama pembelajaran, seperti berperan aktif dalam diskusi kelompok, aktif menjawab pertanyaan dari guru, aktif bertanya kepada guru dan teman, berani mengeluarkan pendapat, dan bersemangat dalam mengikuti pembelajaran. Dari hasil wawancara, peneliti mengetahui bahwa semua itu terjadi karena siswa senang menggunakan media geoboard. "Suka sekali belajar dengan geoboard. "Jadi semangat," ungkap siswa RN. Hal ini sejalan dengan pernyataan Amir (2014) bahwa dengan menggunakan media, siswa menjadi lebih mudah dalam memahami konsep yang dipelajari. Hal tersebut terjadi karena pembelajarannya melibatkan aktivitas fisik dan mental dengan kegiatan melihat, meraba, dan memanipulasi alat peraga yang sejalan dengan karakteristik siswa sekolah dasar yang memiliki rasa ingin tahu yang kuat dan tertarik untuk mengekplorasi situasi di sekitar mereka dengan perasaan senang dan gembira.

Metode, strategi dan keterampilan dalam pengajaran matematika diperlukan untuk membangkitkan minat dan prestasi siswa. Dengan menggunakan metode yang tepat maka tujuan pembelajaran matematika akan tercapai (Margono dan Kusmanto, 2015). 


\section{Istikomah}

Pemanfaatan Geoboard dan Karet Gelang untuk Meningkatkan Minat Belajar Siswa pada Bangun Datar

\section{KESIMPULAN DAN SARAN}

Berdasarkan penelitian yang dilakukan dengan penelitian tindakan kelas pada pembelajaran matematika materi luas dan keliling segitiga dan segiempat dengan menggunakan media geoboard dan karet gelang mampu meningkatkan minat belajar siswa. Dengan penelitian yang dilakukan dalam dua siklus juga dapat terlihat peningkatan hasil belajar maupun pemahaman konsep matematika dengan baik. Maka dengan demikian, penggunaan media pembelajaran dengan geoboard dan karet gelang dapat dijadikan sebagai alternativ untuk mengembangkan inovasi pembelajaran matematika di sekolah dasar.

\section{DAFTAR RUJUKAN}

Amir, Almira. (2014). Pembelajaran Matematika SD dengan Menggunakan Media Manipulatif. Forum Pedagogik, VI(1), 72-89.

Basonggo, Tangkas, Said. (2015). Meningkatkan Hasil Belajar Siswa Melalui MetodeEksperimen dalam Pembelajaran IPA di Kelas V SDN Meselesek. Jurnal Kreatif Tadulako, 2(2), 96-104.

Dolhasair, Istiyati, Harsono. (2017). Penggunaan Media Geoboard (Papan Berpaku) untuk Meningkatkan Pemahaman Konsep Bangun Datar pada Siswa Kelas II Sekolah Dasar. Didaktika Dwija Indria, 5(1).

Fifko, Hardianto. (2017). Meningkatkan Minat Belajar Matematika Melalui Media Dekak Multifungsi Di Sekolah Dasar. Jurnal Pendidikan Guru Sekolah Dasar, 3(1), 215-222.

Keraf, Yohanes Lagadoni. (2017). Penggunaan Media Papan Berpaku untuk Meningkatkan Hasil Berlajar Matematika. Jurnal Pendidikan Guru Sekolah Dasar. 8 (6): 824-830.

Lastrijanah, Prasetyo, Mawardini. (2017). Pengaruh Media Pembelajaran Geoboard Terhadap Hasil Belajar Siswa. Didaktika Tauhidi, 4(2), 87-100.

Margono \& Kusmanto. (2015). Upaya Meningkatkan Minat dan Prestasi Belajar Matematika Menggunakan Metode Permainan Pada Siswa Kelas V SD N 1 Kayumas Kecamatan Jatinom. UNION: Jurnal Pendidikan Matematika, 3(2), 161-168.

Purba, Sariannauli. (2017). Meningkatkan Hasil Belajar Matematika Siswa dengan Menggunakan Metode Demonstrasi pada Siswa Kelas IV SD Negeri 162091 Kota Tebing Tinggi. Elementary School Journal PGSD, 7(2), 225-238.

Silviani, Jailani, Lusyana, Hadi. (2017). Upaya Meningkatkan Minat Belajar Matematika Menggunakan Inquiry Based Learning Setting Group Investigation. Kreano, 8(2), 150-161.

Sitorus \& Siburian. (2013). Meningkatkan Minat Belajar Siswa dengan Menggunakan Pendekatan Kontekstual pada Pokok Bahasan Penjumlahan Pecahan di Kelas V SD Negeri No. 015897 Buntu Pane. Jurnal Handayani, 1(1), 9-18. 


\section{Istikomah}

Pemanfaatan Geoboard dan Karet Gelang untuk Meningkatkan Minat Belajar Siswa pada Bangun Datar

Sundayana. (2016). Media dan Alat Peraga Dalam Pembelajaran Matematika. Bandung: Alfabeta.

Susilowati, Dwi. (2018). Penelitian Tindakan Kelas (PTK) Solusi Alternatif Problematika Pembelajaran. Edunomika, 2(1), 36-46.

Syahbana, Ali. (2014). Alternatif Pemahaman Konsep Umum Luas Daerah Suatu Bangun Datar. Edumatica, 4(2), 11-18.

Utami, Wicka Yunita. (2013). Meningkatkan Minat Belajar Matematika Melalui Permainan Teka-Teki. Jurnal Ilmiah VISI P2TK PAUD NI, 8(1), 1-9.

Widyastuti, Wijaya, Rumite, Marpaung. (2019). Minat Siswa Terhadap Matematika dan Hubungannya dengan Metode Pembelajaran dan Efikasi Diri. Jurnal Pendidikan Matematika, 13(1), 83-100. 